\title{
Circulando com os meninos: infância, participação e aprendizagens de meninos indígenas Xakriabá
}

\author{
Rogerio Correia Silva ${ }^{1}$ \\ rogex.correia@gmail.com
}

\begin{abstract}
Resumo
O objetivo do presente estudo é investigar as formas de sociabilidade, a transmissão do conhecimento e o aprendizado da criança na sociedade indígena Xakriabá. O trabalho lança um olhar mais atento às interações sociais em que meninos acima de oito anos de idade participam, mais especificamente, dos seus modos de participação nas comunidades de prática de seu grupo social. Quando tratamos da infância em grupos indígenas, reconhecemos as especificidades de seus processos históricoculturais, muito distintos dos vividos pela sociedade ocidental, o que garante, por sua vez, outras possibilidades de construção social da infância. As crianças participariam de "forma engajada" nas tarefas diárias a elas atribuídas de acordo com a idade e o gênero. Buscávamos com isso estabelecer outro parâmetro para rediscutir o processo de transmissão do conhecimento e do próprio conceito de cultura.
\end{abstract}

Palavras-Chave: educação indígena, criança indígena, participação, aprendizagem

\section{Introdução}

A presente pesquisa trata das formas de sociabilidade, da transmissão do conhecimento e do aprendizado da criança na sociedade indígena Xakriabá. O trabalho lança um olhar mais atento às interações sociais e

1 Faculdade de Educação da Universidade Federal de Minas Gerais. Doutor em Educação pela UFMG. 
aos modos de participação de meninos acima de oito anos de idade nas atividades cotidianas de seu grupo social.

O grupo indígena Xakriabá habita a região norte do Estado de Minas Gerais, Brasil, na cidade de São João das Missões, no Vale do São Francisco. Com aproximadamente 7.000 pessoas (ocupando uma região de um pouco mais de 53 mil hectares), constitui a maior população indígena do estado. As crianças Xakriabá correspondem a quase metade da população total ${ }^{2}$. Os Xakriabá organizam sua produção em torno da plantação de roças e da criação de animais, destinados ao próprio consumo. Por problemas socioambientais ligados ao uso e degradação do território, sua produção se tornou, ao longo dos anos, insuficiente para subsistência da população, o que exige o deslocamento, durante determinados períodos do ano, de parte significativa da população adulta e jovem masculina para outros estados em busca de trabalho, como as regiões de corte de cana nos Estados de São Paulo e Mato Grosso. A busca de trabalho assalariado é muito acentuado entre os meninos, logo que atingem a idade em torno dos 16 anos. A ausência dos homens da terra indígena por longos períodos no ano aumenta ainda mais a impressão de estarmos numa terra constituída por crianças, jovens, mulheres e velhos, principalmente as primeiras, por circularem mais pela aldeia.

Buscaremos situar o nosso trabalho no campo de estudos sociais da infância e da criança (antropologia e sociologia) em interface com os estudos sobre a cultura e aprendizagem. Faremos uma breve revisão dos estudos sobre as crianças indígenas, dando destaque à crítica a um de seus conceitos mais importantes, ou seja, a "socialização". Nosso estudo também se estrutura a partir da teoria formulada por Lave e Wenger (2003) sobre "modos de aprendizagem e coparticipação da criança no processo", definidas pela expressão "comunidades de prática". Acompanhamos a circulação dos meninos pelo território indígena e suas participações em quatro atividades: o trabalho em casa, na roça, a criação do gado e as caçadas. Neste trabalho, abordaremos a circulação dos meninos por

2 Em 2004, o número de habitantes com menos de 20 anos correspondia há pouco mais de $55 \%$, sendo que o grupo composto por crianças e jovens ( 0 a 14 anos) chegava a $45,12 \%$. As maiores concentrações da população Xakriabá ocorriam nas faixas etárias de menor idade ( 0 até 9 anos), que juntas totalizavam 42,7\% (PENA, 2004; GOMES et al., 2006). 
dois importantes espaços: a casa e a roça. Buscamos estabelecer outros parâmetros para tratar do processo de transmissão do conhecimento e do próprio conceito de cultura entre crianças e adultos indígenas.

\section{Os estudos das crianças indígenas e crítica ao conceito de socialização}

Quando tratamos da infância vivida em grupos indígenas, reconhecemos as especificidades de seus processos histórico-culturais, muito distintos dos vividos pela sociedade ocidental, o que garante outras possibilidades de construção social da infância. Encontraremos nas culturas indígenas outras formas de demarcação e de sociabilidade infantil.

Ao tratarmos dos primeiros estudos sobre crianças indígenas realizados no Brasil, dois deles são pioneiros: o de Fernandes (1966), sobre a socialização entre os Tupinambá, e o de Schaden (1945), sobre as crianças Guarani. Tais estudos trazem contribuições sobre a educação e o lugar da criança nas sociedades indígenas brasileiras. Ambos os autores tratam do aprendizado da criança indígena a partir de atividades cotidianas, da observação da ação exemplar dos adultos, da sua participação e imitação das atividades desenvolvidas na aldeia, reconhecendo também os rituais como importantes momentos formalizados de aprendizado. É inegável a influência que tais estudos sofreram tanto da corrente americana da cultura e personalidade (Margareth Mead), quanto da corrente britânica estrutural funcionalista (Radiclief-Brow). Da primeira, ao trabalharem com uma noção de cultura que constrange a agência das crianças, da socialização ${ }^{3}$ como via de mão única ou de um adulto ideal como um fim último do processo de desenvolvimento em que a criança participa. Da segunda corrente, a ideia de socialização é vista como um conjunto de práticas que tem como objetivo a inserção dos indivíduos em categorias sociais que conformam um sistema. É negada às crianças uma parte ativa na consolidação e definição de seu lugar na sociedade. Elas são vistas como receptáculos de papéis funcionais que desempenham ao longo do

3 Por socialização, estamos entendendo o conceito que “[...] descreve o processo através do qual, pessoas e especialmente as crianças são feitas para assumir as idéias e comportamentos adequados à vida em uma sociedade particular" (TOREN, 1996, p. 512, tradução nossa). 
processo de socialização, interessando apenas a maneira como elas se adaptam às instituições sociais.

A noção de socialização presente nesses estudos tem suas referências em Durkheim, que a concebe como a ação de uma geração mais velha sobre a geração mais nova, algo recorrente em todas as sociedades e épocas históricas. A educação aconteceria através da força de imposição e coerção. Ela culminaria com a interiorização pela criança das normas e valores sociais. Nesse conceito, a criança nasce incompleta e vai se constituindo à medida que recebe a educação por parte dos adultos.

Essa noção de socialização que acomete as crianças, como um aprendizado estático e previsível, pode ter sido responsável pela pouca produção sobre esse grupo social nos campos de estudos da antropologia e etnologia até o final do século XX, ocupando, quando muito, uma posição secundária, sendo sua ação geralmente tratada como extensão da ação dos adultos, sem existência própria. (NUNES, 2003) É na vivência cotidiana da vida em família que as crianças passam a ser mencionadas com maior frequência em temas como concepção e nascimento, socialização e esquemas de aprendizagem, atividades domésticas, parentesco, nominação e preparação de rituais de iniciação à vida adulta.

O movimento de repensar o próprio conceito de socialização foi a tônica da constituição do campo de estudos da infância que começou a se constituir nos anos 80 do século $X X$, reunindo produções das áreas da sociologia e antropologia e passando a se intitular The New Social Studies of Childhood ${ }^{4}$ (NSSC) (SIROTA, 2001; 2005; MONTANDON, 2001; QUINTEIRO, 2005; BOUVIER, 2005; DELGADO; MÜLLER, 2005; GRIGOROWITSCHS, 2008).

As concepções contemporâneas de socialização vão insistir na visão das crianças como atores sociais e produtoras de cultura, ou seja, focam os olhares na construção do ser social (criança) e em sua negociação

\footnotetext{
4 Encontraremos no livro de Alan Prout e Allison James, New paradigm in the sociology of Childhood (NSSC), a síntese das produções e preocupações de outros tantos pesquisadores de vários países (Noruega, Escandinávia, Reino Unido, Estados Unidos, França). A forte crítica à noção de desenvolvimento infantil trazida pela psicologia sobre os estudos da criança, focados, excessivamente, no individual e biológico, crítica que também se estende à noção de socialização com que operavam, baseada na ação de sujeitos plenos (adultos) sobre sujeitos incompletos (crianças) foram pontos de problematização e reelaboração do novo paradigma nas pesquisas da infância, constituindo, assim, um campo de estudos próprio.
} 
crescente com seus próximos (pares, adultos), constituindo, assim, sua identidade. Mobilizados pela ideia de reconhecer o papel ativo da criança no processo, alguns autores chegaram a propor a mudança da nomenclatura "socialização" para enfatizar sua não passividade. Várias foram as propostas de sua superação: o uso de expressões como "processos de socialização" (recuperando os conceitos de SIMMEL; MEAD, "modos de socialização", "administração simbólica da infância", passando por aquelas mais consensualmente aceitas, como a de "reprodução interpretativa" (CORSARO, 2002), até aquelas motivadas pelas revisões críticas diante dos dualismos produzidos pelo próprio campo de estudos (ator-estrutura é um deles), como o uso da metáfora "redes" (PROUT, 2004), enfatizando assim o caráter relacional, dinâmico e complexo do processo.

Entre as abordagens alternativas ao conceito de socialização, optamos pelo uso do conceito "socialidade", tendo como autor referência Georg Simmel e autoras de maior expressão no campo dos estudos da infância, Marylin Strathern e Christina Toren (1998). Para esses autores, não seria apenas a redefinição do conceito de socialização que estaria em jogo, e sim o próprio conceito de sociedade. As críticas a esse modelo recaíram sobre a visão de uma sociedade que agrega partes a um todo; a natureza abstrata atribuída à sociedade, retirando-lhe a possibilidade de concebê-la a partir da vivência concreta; a visão de um indivíduo como entidade autônoma, abstrato, a-histórico e associal, que pré-existe à própria sociedade.

[...] de que a sociedade se constitui real ou formalmente a partir de indivíduos associais, que devem ser socializados, isto é, constrangidos pela inculcação de representações normativas a se comportarem de um modo determinado, e que resistem a esta constrição por uma manipulação egoísta das normas ou pela regressão imaginária a uma liberdade original (VIVEIROS DE CASTRO, 2002, p. 312).

A noção de socialidade surge como uma forma de privilegiar o estudo sobre os modos de constituir o social e agir socialmente. As relações sociais seriam responsáveis por isso e, dessa forma, inerentes 
à existência humana, sendo as pessoas compreendidas como potencial para os relacionamentos, estando inscritas em uma matriz de relação com outros. (STRATHERN, 1996) Socialidade seria entendida como o modo como:

[...] as pessoas se impactam [impinge] umas às outras, produzindo uma estrutura de conhecimentos a partir do qual se possa falar tanto sobre a forma culturalmente constituída quanto dos aspectos normativos destas relações. Concluindo, a socialidade definiria-se a partir do duplo movimento da ação social e moral do estado de estar relacionado (STRATHERN, 2006, p. 153).

Para Viegas (2006), o conceito de socialidade apresenta um grande diferencial em relação ao conceito anterior de sociedade, porque a realidade humana não é abstraída como conjunto de regras, costumes ou estruturas que existem independentemente do indivíduo que participa do processo. Trata, ao contrário, de processos sociais nos quais qualquer pessoa estaria inevitavelmente envolvida (TOREN, 1998), oferecendo um caminho de análise teórica "[...] no qual a vida social ganha sentido no modo imediato como os seres se tornam seres-no-mundo" (VIEGAS, 2006, p. 26 ).

O cotidiano vivido pelas pessoas e suas ações ordinárias ganham visibilidade e se tornam importantes elementos de análise etnográfica. Foi o que pude perceber em nosso trabalho de registro da vida cotidiana entre os Xakriabá. Ao nos voltarmos para as relações internas vividas por um grupo familiar, foi possível captar as visões próprias sobre suas vidas e qual o sentido de viver entre parentes. Como mesmo nos lembra McCallun (1998), socialidade é definida como “[...] um estado momentâneo na vida social de grupo, definido pelo sentimento de bem estar e pelo auto-reconhecimento como um grupo de parentes em plena forma" (MCCALLUN, 1998).

Resgatando tal noção aos estudos da infância, vamos encontrar em Christina Toren (1998) uma ideia de como a socialidade se torna essencial para compreender os processos sociais pelos quais vivem as crianças. A infância seria entendida como um espaço de intersubjetividades. 
Dessa forma, a criança aprende sobre o mundo que lhe cerca e toma conhecimento dele nas relações sociais que estabelece com os outros membros da sua comunidade. A ênfase é colocada nas relações sociais entre pessoas, sejam elas adultas ou crianças.

Com relação aos estudos mais recentes sobre crianças indígenas no Brasil, não pretendendo apresentar um painel exaustivo e completo do campo. Podemos citar inicialmente dois trabalhos que se tornaram referência nos estudos sobre criança indígena no Brasil: a pesquisa desenvolvida por Cohn (2000) sobre as crianças Kayapó-Xikrin, e as de Nunes $(1999 ; 2003)$ sobre as crianças Awué Xavante. As duas pesquisas trazem contribuições importantes, em primeiro lugar, porque articulam o tema da infância a categorias mais amplas que se conectam ao debate antropológico contemporâneo, Cohn (2000) com a perspectiva inaugurada por Seeger, Da Matta e Viveiros de Castro (1979) sobre a elaboração de referenciais próprios para os estudos sobre os povos ameríndios, voltados para a noção de pessoa e corporalidade; Nunes $(1999 ; 2003)$ por analisar como as crianças constroem as noções de espaço e tempo a partir de suas brincadeiras. Ambas as autoras propuseram que as produções infantis ganhassem maior visibilidade nos estudos sobre etnologia indígena, na medida em que esse grupo social trazia contribuições importantes para o estudo das sociedades indígenas como um todo. As duas pesquisas fazem parte, com outros estudos, do livro Crianças indígenas, ensaios antropológicos (SILVA; NUNES; MACEDO, 2002), que reuniu uma coletânea de estudos desenvolvidos por vários pesquisadores constituindo um movimento que inaugura o campo de estudos sobre antropologia da criança no Brasil e trazendo, dessa forma, contribuições significativas da etnologia indígena brasileira ao debate que ocorria sobre a infância no mundo inteiro.

Dentre os trabalhos mais recentes, podemos citar o de Limulja (2007), sobre corporalidade e escola indígena entre as crianças Kaingang e Guarani; o de Oliveira (2004), sobre as crianças Guarani de M’Biruçu e a ação que desempenham na valorização da tradição de Guarani; o de Alvares (2004), sobre a centralidade das crianças Maxakali na comunicação entre o mundo dos vivos e o mundo dos espíritos; o de 
Codonho (2007), que trata da aprendizagem horizontal entre as crianças Galibi-Marworno; o de Lecznieski (2005), sobre o rapto das crianças Kadiwéu; por fim, citamos o de Mubarac Sobrinho (2009), sobre a infância de crianças indígenas urbanas, tratando do cotidiano vivido pelas crianças Sateré-Mawé na cidade de Manaus e sua relação com a escola.

Tassinari (2007, 2009) faz uma síntese das pesquisas produzidas sobre crianças indígenas quando destaca cinco aspectos recorrentes e marcantes da forma diferenciada como os povos indígenas concebem e vivenciam a infância:

$1^{\circ} \mathrm{o}$ reconhecimento da autonomia da criança e de sua capacidade de decisão: os grupos indígenas reconhecem a capacidade de agência da criança na tomada de decisões (em alguns grupos a decisão de nascer e permanecer ou não neste mundo) que afetam não somente sua vida, mas as de seus pais, familiares, comunidade; a autonomia passa também por conceber o aprendizado levando em conta a iniciativa da criança de buscar por ela mesma o conhecimento;

$2^{\circ}$ o reconhecimento das diferentes habilidades das crianças frente aos adultos. A onipresença das crianças indígenas em todos os lugares da aldeia constitui parte importante de sua educação, uma vez que, quando se torna adulto, o indivíduo tenha conhecimento da vida na comunidade, embora não seja mais permitida sua circulação a todos os lugares da aldeia; trata também da importância do processo de socialização que acontece entre os pares e da tolerância e valorização por parte do adulto de suas produções;

$3^{\circ}$ a educação como produção de corpos saudáveis: trata aqui da educação voltada para a preparação dos corpos para aprendizagem, definindo-a mais a partir do fazer, da observação, das ações cotidianas do que falar propriamente sobre ela; diferente da autonomia aqui não há margem de escolha para a criança, o corpo é preparado a partir da ingestão de alimentos em certas fases da vida e em certas circunstâncias, da mesma forma que alguns alimentos são proibidos e evitados; os cuidados com a educação são os mesmos que visam sua saúde e bem-estar, voltada para "a produção de 
corpos saudáveis e belos, bem desenvolvidos e ornamentados" (COHN, 2002);

$4^{\circ}$ o papel da criança como mediadora de diversas entidades cósmicas, por não estarem totalmente assimiladas à categoria humana; trata do constante jogo de produção e predação da criança, exercido pelas diversas categorias de seres que habitam o cosmos;

$5^{\circ}$ o papel que a criança cumpre na construção e reprodução da organização social e como mediadora dos diversos grupos sociais: define aqui o espaço de sociabilidade da criança indígena que é o espaço familiar, da convivência com aqueles que partilham dos mesmos alimentos e substâncias corporais. A criança desempenhando um importante papel na construção dos laços de parentesco, sendo ele muitas vezes a própria criança, aquilo que se produz e ao mesmo tempo se partilha. Em nosso trabalho, estabelecemos um diálogo mais estreito com estas produções sobre as crianças indígenas, principalmente no que ser refere ao reconhecimento da agência da criança, da sua autonomia, do papel como mediadora dos diversos grupos sociais, da sua onipresença nos espaços da aldeia e da analises sobre a educação da criança como produção de corpos saudáveis (SEEGER, DA MATTA E VIVEIROS DE CASTRO, 1979; COHN, 2000) 5 .

\section{Aprendizagem situada em comunidades de prática}

Um segundo conceito imprescindível na constituição de nossa investigação é o de "aprendizagem situada em comunidades de prática", formulado por Lave e Wenger (2003). Nesse conceito, a aprendizagem constitui um aspecto da prática social. Ela seria vista como fruto de um

\footnotetext{
5 Tal perspectiva articula um diálogo mais estreito entre a infância e as noções do campo da etnologia indígena voltadas para o estudo e compreensão das sociabilidades das populações ameríndias: a noção de corporalidade relacionada à noção de pessoa como forma de análise da organização social dessas populações. A maioria das sociedades indígenas das terras baixas do continente sul-americano realiza uma reflexão sobre a corporalidade na elaboração de suas cosmologias, necessitando os pesquisadores recorrerem a temas ligados a essa categoria (concepção, teoria de doenças, proibições alimentares, ornamento corporal, papel dos fluídos corporais no simbolismo geral da sociedade entre outras) para dar conta dos princípios de estruturação social dos grupos. Por sua vez, a construção da corporalidade está vinculada a construção e definição da pessoa pela sociedade.
} 
processo de caráter situado, mediado pela diferença de perspectivas entre coparticipantes e estaria situada em certas formas de coparticipação e não meramente nas mentes das pessoas. Essa prática social que envolve coparticipantes possui um tipo específico de estrutura de participação, na qual o aprendiz adquire habilidades através do seu concreto engajamento no processo e das condições da sua participação periférica legitimada (Legimate Peripheral Participation ou LPP) no contexto de uma comunidade de prática. Sem engajamento não há aprendizagem, e onde o próprio engajamento é sustentado, a aprendizagem ocorrerá.

De orientação fenomenológica, tal perspectiva se contrapõe à validez das descrições das ciências sociais baseadas no estabelecimento de estruturas e códigos pré-fabricados. Nesse sentido, a aprendizagem não constituiria um corpo discreto de conhecimentos abstratos, transportados e reacondicionados a contextos posteriores, predominando a ideia de estruturas autocontidas na qual a aprendizagem e a compreensão se desenvolvem. Como alternativa, tal perspectiva se centra sobre as contribuições produtivas dos atores na ordem social. Ganham destaque nessa concepção aspectos como a negociação, a estratégia e aquilo que é imprescindível: a ação. Nesse sentido, Lave e Wenger (2003) propõem uma revisão das ideias sobre como se dá o processo de aprendizagem, resignificando, com isso, o lugar e o papel da ação e sua relação com as representações mentais do indivíduo. Para elas, aquilo que pode explicar a ação é pensado não de forma isolada em uma relação estrutura-processo: uma ação que gera num momento posterior representações mentais.

$\mathrm{Na}$ ação, tanto a representação mental do indivíduo (estrutura), quanto sua execução habilidosa (processo) são vistas como aspectos que interpenetram profundamente um no outro. A mudança está contida na visão sobre esta relação entre estrutura e processo. A estrutura é mais um resultado variável da ação do que sua pré-condição invariante. Ocorre, com isso, a transposição do problema das representações mentais para os marcos da participação "[...] transposição composta por uma mais sutil e radical mudança de uma estrutura invariante a uma que é menos rígida e mais profundamente adaptativa". Uma consequência disso é, por exemplo, a incorporação de um aspecto negligenciado por outros 
modelos, que é a aprendizagem por improvisação nos casos de interação em curso. Ao reconsiderar os marcos em que se definem o lugar da ação na aprendizagem, tratamos agora de caracterizar esse tipo especial de ação que desencadeia o processo de aprendizagem; as autoras caracterizam essa ação num duplo sentido: uma prática social associada a uma classe de participação periférica legítima (PPL). De forma mais clara, podemos dizer que as ações que dão acesso a processos de aprendizagem são as atividades cotidianas, em que as pessoas coparticipam de tal modo, que ganham acesso a modos de comportamento não disponíveis de outra maneira para eles e desenvolvem certas classes de habilidades adequadas a certas classes de execução. Por exemplo, atletas que treinam juntos; expectadores que assistem a um mesmo evento; crianças que aprendem uma nova brincadeira.

A participação periférica legitimada ${ }^{6}$ é uma característica da aprendizagem como atividade situada. Proporciona uma maneira de falar acerca das relações entre os recém-chegados e os veteranos diante das atividades, identidades, artefatos e comunidades de conhecimento e prática. “Um processo através do qual os recém-chegados se tornam parte de uma comunidade de prática", num movimento da participação periférica para a participação plena. Nessa visão, as intenções do aprendiz são consideradas e o significado da aprendizagem decorre de seu processo de se transformar em um participante pleno de uma prática sócio-cultural. A participação periférica constitui uma noção complexa, pois implica se dar conta das estruturas sociais, que, por sua vez, envolvem relações de poder. Como um lugar no qual se move para participação mais intensiva se torna também uma posição de empoderamento, periferia também é um termo positivo, não no sentido de uma participação parcial, mas de um tipo de participação possibilitada (daí também o sentido de legitimada), que sugere uma abertura, um modo de ganhar acesso a fontes do entendimento através

6 A ideia de periferia adotada nessa definição sugere que existem formas múltiplas, variadas e mais ou menos comprometidas e inclusivas de estar localizado nos campos de participação definidos por uma comunidade. Não existe com isso uma noção linear de aquisição de habilidades, muito menos se trabalha com a ideia da existência de uma periferia como contraponto a existência de um centro ou núcleo. Para as autoras, a ideia de participação periférica corresponde com o estar localizado no mundo social. As localidades e as perspectivas mutantes são partes das trajetórias de aprendizagem dos atores, do desenvolvimento de suas identidades e das formas de se tornar membro do grupo. 
do envolvimento crescente na comunidade de prática. Por participação completa se pretende fazer justiça à diversidade de relações envolvidas nas variadas formas de se tornar membro numa comunidade. Por não se referir a qualquer forma de coparticipação em que ocorra a aprendizagem, a questão formulada pelas autoras sintetiza a importância desta prerrogativa: "quais seriam as classes de compromissos sociais que proporcionam o contexto apropriado para que a aprendizagem tome lugar"? A partir dessa explanação sobre os conceitos de participação periférica legitimada e socialidade, podemos identificar os objetivos de nossa pesquisa, que nos colocam alguns desafios na articulação dessa teoria com a discussão da infância e do lugar da criança na sociedade indígena Xakriabá.

Qual é a infância Xakriabá e qual é o lugar e ao sentido que tal sociedade indígena atribui à criança? Que sociabilidades configuram a infância e o aprendizado da criança Xakriabá, especificamente na vivência cotidiana em seu grupo familiar e na participação das atividades que se configuram como comunidades de prática? Qual é o lugar e a importância dos grupos dos meninos na organização social e na vida econômica da aldeia?

\section{Circulando com os meninos das casas dos parentes para as roças}

Elegemos a circulação das crianças como fio condutor de nossa descrição etnográfica sobre a infância dos meninos Xakriabá. Caminhar ou circular pela aldeia era uma atividade cotidiana presente entre adultos e crianças. Toda a aldeia era um emaranhado de trilhos que levavam a todos os lugares, ligando estradas, cortando as matas, ligando as casas dos parentes, às roças, aos brejos, à escola, às outras aldeias. Circular pelo território podia ter vários significados, como a ideia de "fazer parentes", "garantir o sustento da família", mas também podia significar momentos de encontros e predação. As trilhas e estradas da terra indígena nas quais adultos e crianças circulavam diariamente eram marcadas pela coexistência pacífica ou não com os não humanos, como os espíritos dos mortos (as aleivosias), os seres encantados, as 
cobras e os cachorros ${ }^{7}$.

A intensa circulação das crianças pela aldeia atestava um aspecto importante sobre a infância, que é a presença e participação delas em todas as atividades do grupo - das reuniões na casa da comunidade às cerimônias religiosas, nas festas, nos casamentos, nas atividades domésticas de seu grupo familiar voltadas para manutenção da casa e para o cultivo e preparo de alimentos. Não havia entre os Xakriabá uma distinção entre espaços voltados exclusivamente para adultos e aqueles voltados para as crianças. De situações mais informais até as mais estruturadas e formalizadas de aprendizado, esses diversos momentos da vida social que propiciavam o encontro entre adultos e crianças suscitavam, por sua vez, uma diversidade de situações de comunicação e aprendizagem. Essa maior liberdade de acesso aos lugares e às conversas e atividades realizadas por adultos constitui não só uma parte importante e necessária de sua formação como também uma forma importante de troca entre os grupos familiares e de sociabilidade entre as famílias promovida por essa circulação das crianças. (GOMES, 2008) O primeiro lugar de circulação dos rapazinhos pelo território indígena tem início na própria casa e no quintal onde habitam. É o espaço onde nasceram e, ainda pequenos, iniciam o seu processo de socialização. As crianças são inseridas desde o nascimento na vida de seu grupo doméstico.

No ambiente feminino da casa, as crianças aprendem a andar e a falar, recebem os primeiros cuidados com alimentação e saúde, ações que continuam até quando se tornam rapazinhos, na ideia de "pegarem corpo". É também o lugar de se fazer parentes. Em muitos momentos das análises dos registros do trabalho de campo, foi possível estabelecer relações com as encontradas nos trabalhos de Overing (1999), McCallun (1998) e Viegas (2007), que trataram de descrever e compreender o

6 Adotamos aqui as ideias formuladas sobre pensamento ameríndio a partir do perspectivismo (VIVEIROS DE CASTRO, 1996; LIMA, 1996), em que animais e plantas são vistos como sujeitos sociais, com instituições e comportamentos simétricos aos homens e a ideia de território proposto por Deleuze (1988). O território indígena nos dava a impressão de vários territórios superpostos em que habitavam entidades diferentes (aleivosias, cobras, seres encantados). Era ao mesmo tempo um espaço de circulação dos humanos, mas, em certos momentos e lugares, também se tornavam domínio dessas entidades que, em confronto com os humanos, davam início de movimentos de predação e contrapredação de ambos os lados, em que as cobras ou as aleivosias tomavam a saúde - física ou espiritual - de quem lhes cruzassem o caminho. 
caráter íntimo da vida nativa entre os povos ameríndios. Foi possível, a partir desses estudos, estabelecer um recorte para análise das relações que se dão no interior dos grupos locais e, principalmente, a filosofia moral presente nessas práticas de sociabilidade. “Unidos na irmandade e na comidaria", e, "quando um tem, todos têm" duas expressões muito ouvidas da boca dona Maria Pereira, matriarca do grupo familiar que pesquisava, expressa bem a filosofia moral presente na vida entre parentes, marcada pelo intenso e cotidiano compartilhamento e solicitude entre os seus membros. A produção, as práticas de mutualidade e a ética de consanguinidade têm foco nessas relações.

Ações cotidianas, como o preparo de alimentos, o comer juntos, a troca de produtos, os cuidados com as crianças, as visitas e as rodas conversas são vividas de forma intensa pelo grupo. Essas ações, por exemplo, delimitam os significados da vida entre parentes, mostram-nos que os laços de parentesco não se sustentam a priori e de forma incondicional, precisam da ação cotidiana para serem mantidos e renovados, ao mesmo tempo que novos laços são estabelecidos (as crianças que nascem, os casamentos, a chegada de um genro ou nora), assim como outros entes esquecidos que voltam à cena (a chegada de um parente que há vários anos vive fora do território, em São Paulo). Alguns também são desfeitos.

As crianças pequenas iniciam sua participação nas atividades da casa ainda cedo, tão logo comecem a andar. Podemos perceber gradações diferentes desta sua participação. Quase sempre elas testemunham as atividades realizadas na casa ou quintal, chegando próximas às pessoas que a executam e apenas observam. Isso é uma característica muito forte entre elas. Outras vezes elas participam voluntariamente de pequenas ações, como ajudar a carregar um pouco de capim para os cavalos; as crianças maiores carregam o fardo maior, o que já seria considerado um segundo tipo de participação. O que diferencia das outras crianças maiores é que a criança pequena decide quando entra e quando sai da tarefa, com o consentimento dos adultos. Estar presente e observar, a participação voluntária em atividades adaptadas à idade e ao tamanho da criança, a possibilidade de interromper a qualquer momento sua participação poderiam ser consideradas condições atenuadas de uma 
participação periférica por parte do aprendiz. A responsabilidade de o menino maior cuidar do menor, ao mesmo tempo que realiza outras tarefas, estreita ainda mais a proximidade entre os pequenos e as atividades. Podemos ver crianças acima dos quatro anos realizando pequenos serviços, como reunir gravetos para o fogão, juntar porcos, descascar milho ou feijão, espantar as galinhas, buscar água.

No caso das meninas, além dessas tarefas, existem outras mais específicas que envolvem mais diretamente o cuidado com a casa, como varrer, lavar vasilhas, lavar roupa. Como já relatamos, nessas ocasiões, as crianças estão sempre acompanhadas de outra criança mais velha ou de um adulto, que realiza a mesma atividade. Aos poucos, as crianças começam a realizar algumas dessas tarefas sozinhas, sem a ajuda ou participação de outra criança ou adulto. As crianças aprendiam ainda cedo o caminho das casas dos parentes. Quando muito pequenas, as crianças acompanham os pais nas visitas, mas, a partir dos seis anos de idade, assistimos a meninos e meninas em pequenos grupos ou sozinhos realizando rápidas visitas, levando e trazendo recados, pedidos, fazendo pequenas tarefas. As crianças circulavam pela casa mais até que os próprios adultos, porque, além de visitarem os parentes a pedido dos adultos, iam também por conta própria, para encontrarem com seus grupos de pares.

Na proximidade da idade de sete, oito anos, as saídas das crianças para acompanhar os pais no trabalho da roça, que já aconteciam, mas de forma esporádica, passam a ocorrer com maior intensidade e a participação delas já começa a contar de forma mais efetiva para o trabalho a ser realizado pela família. Nessa época, a criança participa do trabalho realizando pequenas tarefas de acordo com sua força e habilidades, como abrir pequenas covas, jogar as sementes nos buracos ou tampá-los. Ela aprende a capinar pequenas porções de capim ainda no terreiro de casa, mas ainda é considerado cedo colocá-los nessa atividade. É quando o pai prepara uma enxada do tamanho da criança para ela realizar o serviço. Os meninos, a partir dos oito anos de idade - "os rapazinhos" - são inseridos de forma mais efetiva nas tarefas realizadas pelo grupo dos homens e tendo a partir daí um importante 
papel na organização da vida familiar, bem como na socialização das crianças pequenas. Teriam assim uma dupla função: ensinam às crianças pequenas as tarefas que elas futuramente desempenharão e, ao mesmo tempo, inserem-nas na ideia de divisão sexual do trabalho. Os rapazinhos têm um importante peso na economia familiar, na medida em que, com as mulheres, ocupam hoje, os espaços no trabalho da roça e na criação de gado deixados pelos homens que viajam para trabalhos temporários nas usinas de cana-de-açúcar.

As saídas para a roça e o tipo de serviço que adultos e crianças lá executarão estão ligados às várias das etapas da produção e cultivo dos alimentos, que vão desde o preparo do terreno ou "a limpa" (retirada do mato e arbustos, derrubada de um pedaço de mata, ou, em se tratando do terreno já utilizado, a retirada da plantação anterior), "a coivara" (o que corresponde à queima do material vegetal derrubado), do plantio (que pode envolver tarefas como arar o terreno, a abertura de covas, a semeadura), das visitas para manutenção e limpeza do terreno até a colheita, para em seguida se reiniciar todo o processo. $O$ trabalho é feito ao longo de todo o ano, com períodos de intensa atividade, envolvimento e participação de todo o grupo (plantio e colheita) intercalados por períodos de menor atividade.

Os ciclos das chuvas e de estiagem orientam o processo de produção agrícola. Sendo assim, existem também períodos de espera em que, após a colheita, o grupo aguarda as próximas chuvas (preparando o terreno quando se aproxima da época) para que iniciem o plantio de uma nova roça. Embora seja difícil precisar uma divisão sexual das tarefas realizadas entre homens e mulheres no trabalho da roça, os Xakriabá não têm dúvidas de que são os homens quem teriam autoridade para ensinar aos meninos o ofício. Todavia, mesmo que essa informação esteja correta, verificamos que tal processo não ocorre da maneira prescrita pelo grupo. Diante das saídas dos homens do território para os trabalhos nos cortes de cana, os meninos nos Xakriabá passam a aprender o seu oficio de roça e as responsabilidades que lhes competem com as mulheres. Uma das primeiras e mais importantes atividades que os meninos aprendem no trabalho da roça é a de capinar. Começa-se quando um adulto, nesse 
caso o pai ou um homem próximo aos meninos, constroi uma enxada nas dimensões reduzidas e adaptadas ao tamanho das crianças. Além de acompanhar os adultos nas idas diárias à roça, as crianças iniciam por capinar e por manter o próprio terreiro ao redor da casa limpo ou mesmo preparado para o plantio. Foi o que constatei em diversas ocasiões em que estive em diferentes casas quando os meninos costumavam mostrarme as extensões dos terrenos ao redor da casa que mantinham limpos e sob sua responsabilidade, ou mesmo que preparavam para o plantio. As saídas para a roça acontecem concomitantemente a estas tarefas realizadas próxima à casa. Se antes essa saída para a roça acontecia de forma esporádica, a partir daí se tornam mais frequentes e formalizadas. Muda-se também a forma de participação das crianças nas atividades.

Quando as crianças eram menores, suas participações eram voluntárias e elas podiam abandonar a tarefa que realizavam a qualquer momento. Agora que já cresceram, os meninos precisam "dar conta" dessa atividade até o final. Mesmo assim, essas atividades são diferenciadas das dos adultos no que se refere ao esforço, a extensão do trabalho a ser realizado e ao tempo de execução e de descanso. Há, por exemplo, tempo para brincar, existe um cuidado por parte dos adultos em protegê-los do sol quente, escolhe-se áreas que sejam mais fáceis de capinar, capinam os meninos separados dos adultos. Uma estratégia relatada por um pai sobre como orientava seus filhos na roça era atribuir-lhes no início pequenas tarefas, como capinar locais onde o capim ainda estava novo e exigia pouco esforço para retirá-lo. A partir de certa idade, costumava dividir o terreno da roça pelos filhos e atribuía-lhes a responsabilidade pela manutenção de determinado espaço. Durante o trabalho na roça, as orientações eram dadas in loco e no instante em que o ato acontecia.

À medida que crescem e adquirem maior tônus muscular e habilidade, os meninos vão aumentando a extensão do terreno a ser capinado. Assumem também outras atividades que se referem ao trabalho da roça como, por exemplo, o ofício de "bater foice". Ele exige um pouco mais de força e são realizados nos momentos em que se opera a limpa do terreno, cortando o mato e derrubando pequenos arbustos. Exige, ainda, o domínio da foice, um objeto cortante muito afiado, embora não 
seja novidade para as crianças o uso cotidiano de objetos como facas e o facão. Exige, também, um domínio de uma série de técnicas para cortar. Como pude verificar certa vez, em que acompanhei seu Servino, seus dois filhos e seu cunhado para um serviço de limpa num dos terrenos que preparava para as próximas águas. O terreno era bastante extenso e ficava numa das partes mais altas da aldeia, já próximo à estrada de rodagem que levava à aldeia de Sumaré. Fazia alguns anos que seu Servino não plantava ali e os arbustos haviam crescido por toda a parte. Logo que chegamos, procuramos um enorme e frondoso pé de umbu', em que deixamos a água e as bolsas, e os meninos retiraram do embornal uma lima de ferro e começaram imediatamente a amolar suas foices. Logo que terminaram os homens se dirigiram para uma parte do terreno enquanto os dois meninos permaneceram próximos à arvore. Tanto os homens, quanto os meninos trabalhavam em duplas um ao lado do outro, mantendo entre si certa distância segura por causa da foice, mas desbastando uma área comum.

O trabalho na roça molda os corpos dos meninos. É importante ponto de discussão sobre a construção e fabricação do corpo belo e saudável que tanto diz os estudos de etnografia indígena. Um aspecto importante que nos chama a atenção é que a execução da atividade pelos meninos modifica seus corpos, constitui e enfatiza uma musculatura própria e específica, que, por sua vez, influencia na performance da ação. Essa ideia está presente naquilo que os Xakriabá dizem sobre a necessidade dos meninos "pegarem corpo". Uma vez que os meninos são inseridos nas atividades do trabalho na roça, as preocupações dos adultos se voltam para o fortalecimento desse corpo. "Pegar corpo" pode significar tornar o corpo forte, robusto, apto para o trabalho. Ter um corpo forte não significa ter habilidade para realizar as tarefas. Dessa forma, estamos falando de um corpo que se fortalece no aprendizado de uma habilidade. Os homens dizem que uma condição para que os meninos aprendam todo o oficio do trabalho na roça seria além de saber manusear as ferramentas, adquirirem a força física para tal, "pegarem corpo".

Apesar do intenso aprendizado pelo que passam, ainda não

8 Arvore frutífera muito presente no cerrado 
adquiriram a força suficiente, a compleição física necessária para dar conta de todas as tarefas do trabalho na roça, como o manejo da foice e do machado. Ao mesmo tempo, avaliam que a única forma para que isso aconteça seria continuar trabalhando à medida que crescem. $\mathrm{O}$ corpo não se desenvolveria apenas com a idade, não fora do trabalho. Ter força física, realizar tarefas como o uso do machado são atribuições dos homens. Os homens se surpreendem quando as mulheres assim procedem, quando usam o machado, constroem cercas ou demonstram possuir uma força física que as igualam aos homens. Para os Xakriabá, um corpo saudável seria, nesse sentido, um corpo voltado para o trabalho e que resista às intempéries do ofício. É um corpo que se fortalece, atento ao efeito que determinados alimentos podem lhes provocar. Também um corpo sujeito às doenças provocadas por entidades que povoam o território (mortos, cobras, feitiços), que, nesse sentido, podem lhes causar algo que Deleuze (1988) chama de "desterritorialização".

Acreditamos que exista uma forte conexão entre a ideia de pegar corpo, o trabalho na roça e a constituição da identidade masculina entre os Xakriabá. Homens e meninos compartilham das mesmas experiências, tendo o trabalho na terra e a apropriação do espaço territorial indígena como elementos importantes da construção identitária de ambos. A dimensão do trabalho na roça produz uma identidade masculina nos meninos. Ele ensina, entre outras coisas, a forte ligação dos Xakriabá com a terra, o valor atribuído a essa tarefa pelo grupo: como aquilo que os une e garante a subsistência da família. Fortalece, também, a ideia do que é ser homem e do que é ser mulher no grupo. O trabalho na terra é uma preocupação do homem e é sua responsabilidade garantir, através dele, o sustento da família. Ser homem é trabalhar na roça, ter o corpo desenvolvido para o serviço, possuir força e técnica para manusear os instrumentos, dominar os conhecimentos necessários para a produção.

A circulação dos meninos entre os espaços da casa e da roça e os aprendizados decorrentes da forma tanto como se inserem, mas também como se estruturam as atividades e garantem sua participação nos dão mostra dos processos de socialização da criança nessas interações. Uma primeira constatação que podemos fazer é a de que a infância é uma 
categoria relacional, no sentido de articular outras categorias (gênero, aprendiz, idade). Numa concepção de infância indígena, o mundo das crianças e o mundo dos adultos não estão separados, pelo contrário, estão profundamente interligados. Na ação e participação das crianças em seu grupo familiar e comunitário, reconhece-se que os meninos Xakriabá, na medida em que aprendem, desempenham um papel fundamental na manutenção do seu próprio grupo. 


\section{Referências}

ALVARES, Myriam. Kitoko Maxakali: a criança indígena e os processos de formação, aprendizagem e escolarização. Revista Anthropológicas, ano 8, v. 15, n. 1, p. 49-78, 2004.

BOUVIER, Suzanne Mollo. Transformação dos modos de socialização das crianças: uma abordagem sociológica. Educação \& Sociedade, v. 91, n. 26, p. 391-404, maio/ago. 2005.

CODONHO, Camila Guedes. Aprendendo entre pares: a transmissão horizontal de saberes entre as crianças indígenas Galibi-Marworno. Dissertação (Mestrado em Antropologia) -Universidade Federal de Santa Catarina, Florianópolis, 2007.

COHN, Clarice. A criança indígena: a concepção Xikrin de infância e aprendizado. Dissertação (Mestrado em Antropologia) Departamento de Antropologia, Universidade de São Paulo, São Paulo, 2000.

CORSARO, Willian. A reprodução interpretativa no brincar ao "fazde-conta" das crianças. Revista Educação Sociedade e Culturas, v. 17, p. 113-134, 2002.

O ABECEDÁRIO de Gilles Deleuze. Direção: Pierre-André Boutang. França: Éditions Montparnasse, 1988. 158 min.

DELGADO, Ana C.; MÜLLER, Fernanda. Em busca de metodologias investigativas com as crianças e suas culturas. Cadernos de Pesquisa, v. 35, n. 125, 2005.

FERNANDES, Florestan. Notas sobre a educação na sociedade Tupinambá. In: Educação e sociedade no Brasil. São Paulo: Dominus; Edusp, 1966, p. 144-201. 
GOMES, Ana Maria R. Outras crianças, outras infâncias? In: SARMENTO, Manuel; GOUVEIA, Maria Cristina Gouvea (org.). Estudos sobre infância: educação e práticas sociais. Petrópolis: Vozes, 2008, p. 82-96.

GRIGOROWITSCHS, Tâmara. O conceito de "socialização" caiu em desuso? Uma análise dos processos de socialização na infância com base em Georg Simmel e George H. Mead. Educação \& Sociedade, v. 29, n. 102, p. 33-54, jan./abr. 2008.

LAVE, Jean; WENGER, Etienne. Aprendizaje situado: participación periférica legitima. Tradução Raul O. Ramírez. Universidade Autônoma de México: México, 2003.

LECZNIESKI, Lisiane. Uma economia política de crianças. In: Estranhos laços: predação e cuidado entre os Kadiwéu. Tese (Doutorado em Antropologia Social) - Programa de Pós-Graduação em Antropologia Social, Universidade Federal de Santa Catarina, Florianópolis, 2005.

LIMA, Tânia Stolze. Os dois e seu múltiplo: reflexões sobre o perspectivismo em uma cosmologia Tupi. Mana, v. 2, n. 2, p. 21-47, 1996.

LIMULJA, Hanna. Uma etnografia da escola indígena Fen'Nó à luz da noção de corpo e das experiências das crianças Kaingang e Guarani. Dissertação (Mestrado em Antropologia Social) - Programa de PósGraduação em Antropologia Social, Universidade Federal de Santa Catarina, Florianópolis, 2007.

LOPES DA SILVA, Aracy; NUNES, Angela; MACEDO, Ana Maria. (org.). Crianças Indígenas, ensaios antropológicos. São Paulo: Mari/ Fapesp/Global, 2002.

MCCALLUN, Cecília. Alteridade e sociabilidade Kaxinauá: 
perspectivas de uma antropologia da vida diária. Revista Brasileira de Ciências Sociais, v. 13, n.38, out. 1998.

MONTANDON, Cleopâtre. Sociologia da infância: balanços dos trabalhos em língua inglesa. Cadernos de Pesquisa, n. 112, p. 33-60, mar. 2001.

MUBARAC SOBRINHO, Roberto Sanches. Vozes infantis: as culturas das crianças Sateré-Mawé como elementos de (des)encontros com as culturas da escola. Tese (Doutorado em Educação) - Programa de PósGraduação em Educação, Universidade Federal de Santa Catarina, Florianópolis, 2009.

NUNES, Angela. A sociedade das crianças A'uwê-Xavante - por uma antropologia da criança. Lisboa: Instituto de Inovação Educacional/ Ministério da Educação, 1999.

NUNES, Angela. Brincando de ser criança: contribuições da etnologia indígena brasileira à antropologia da infância. Tese (Doutorado em Antropologia) - Departamento de Antropologia, Lisboa, Portugal, 2003.

OLIVEIRA, Melissa Santana de. Kyringuè i Kuery Guarani: infância, educação e religião entre os Guarani de M'Biguaçu. Dissertação (Mestrado em Antropologia Social) - Programa de Pós-Graduação em Antropologia Social, Universidade Federal de Santa Catarina, Florianópolis, 2004.

OVERING, Joanna. Elogio do cotidiano: a confiança e a arte da vida social em uma comunidade amazônica. Mana, v.5, n. 1, 1999.

PROUT, Alan. Reconsiderar a nova sociologia da infância. Tradução de Helena Antunes. Braga: Universidade do Minho; Instituto de Estudos da Criança, 2004. (mimeo) 
QUINTEIRO, Jucirema. Infância e educação no Brasil: um campo de estudos em construção. In: FARIA, Ana Lucia Goulart de; DEMARTINI, Leila de Brito Fabri; PRADO, Patrícia Dias (org.). Por uma cultura da infância. Campinas: Autores Associados, 2005. p. 19-47.

SCHADEN, Egon. Educação e magia nas cerimônias de iniciação. Revista Brasileira de Estudos Pedagógicos, v. 3, n. 8, p. 271-274, fev. 1945.

SEEGER, Anthony; DA MATTA, Roberto; VIVEIROS DE CASTRO, Eduardo. A construção da pessoa nas sociedades indígenas brasileiras. Boletim do Museu Nacional, n. 32, 1979.

SIROTA, Regine. Emergência de uma sociologia da infância: evolução do objeto e do olhar. Cadernos de Pesquisa, n. 112, p. 7-31, mar. 2001.

STRATHERN, Marilyn. The concept of society is theoretically obsolete. In: INGOLD, Tim. Key debates in anthropology. London; New York: Routledge, 1996. p. 60-66

STRATHERN, Marilyn. O gênero da dádiva: problemas com as mulheres e problemas com a sociedade na Melanésia. Tradução André Villa Lobos. Campinas: Editora Unicamp, 2006.

TASSINARI, Antonella. Concepções indígenas de infância no Brasil. Revista Tellus, ano 7, n. 13, p. 11-25, out. 2007.

TASSINARI, Antonella. Múltiplas infâncias: o que a criança indígena pode ensinar para quem já foi à escola - ou a sociedade contra a escola. In: ENCONTRO ANUAL DA ANPOCS, 33., Caxambu, MG, 2009.

TOREN, Christina. Socialization. In: BANARD, Alan; SPENCER, Jonathan. Encyclopedia of social and cultural anthropology. London: Routledge, 1998. p. 512-514. 
VIEGAS, Susana de Matos. Terra calada: os Tupinambá na mata atlântica do sul da Bahia. Rio de Janeiro: 7 Letras, 2007.

VIVEIROS DE CASTRO, Eduardo. O conceito de sociedade em antropologia. In: VIVEIROS DE CASTRO, Eduardo (org.). A inconstância da alma selvagem e outros ensaios. São Paulo: Cosac Naify, 2002. p. 295- 316. 


\title{
Hanging with the boys: childhood, participation and learning of indigenous boys Xakriabá
}

\begin{abstract}
The present study's objective is to investigate the sociability forms, the knowledge transmission and children learning at Xakriabá indigenous society. The work takes a closer look at the social interactions that boys above eight years old take part, more specifically, their ways of participation at the practice community of their social group. When dealing with childhood at indigenous groups, we recognize the specificity of their historical-cultural processes, a lot different from the ones experienced by the occidental society, what grants other possibilities to the social construction of childhood.The children would participate in an "engaging way" at the daily duties attributed to them according to their age and gender. With this we sought to establish another parameter to rediscuss the knowledge transmission process and the Culture concept itself.
\end{abstract}

Keywords: indigenous education, indigenous child, participation, learning

Recebido: 21/11/2012

Aprovado: 27/12/2012 